\title{
Maestro de anestesiología Jorge Dagnino Sepúlveda
}

Puerto Varas, noviembre 2015

Señores presidente y miembros del directorio de la Sociedad de Anestesiología de Chile, estimados invitados extranjeros, amigas y amigos, colegas, señoras y señores. En primer lugar, quisiera agradecer muy sinceramente al directorio de nuestra sociedad el haberme conferido esta distinción y agradecer también la suerte de que esta ceremonia se haga en este extraordinario marco del Teatro del Lago, tan lleno de recuerdos musicales y entre tantas caras conocidas y queridas en el auditorio. Agradezco, y me alegro también, que en esta ceremonia coincidamos con Ricardo Bustamante con quien me une una larga amistad, desde que el era chico, pienso que porque siempre hemos respetado nuestras diferencias y disfrutado continuamente de nuestras coincidencias. Y agradezco a Mario Concha por sus cariñosas palabras, que creo obedecen más a una también larga amistad que a un juicio crítico, y que me traen a la memoria una anécdota relatada por un gran amigo cirujano, muchos de ustedes imaginaran quien, quien me comentó que estas presentaciones eran como escuchar lo que dirán de uno en el funeral, ese antiguo nihil malum mortuis, nada malo de los muertos y, por extensión, supongo, nada malo de los maestros.

Debo confesar que la noticia sobre esta decisión del directorio evocó en mí pensamientos y emociones contradictorias que persisten hasta este instante: pudor, por estar expuesto al escrutinio público, algo que he tratado de rehuir siempre hasta donde me ha sido posible; orgullo, pues es un reconocimiento a toda una vida dedicada a la anestesiología, especialidad vasta y fascinante; humildad, por tener clara consciencia de las limitaciones que superan los méritos, algo que siempre sabemos aunque no siempre reconocemos; y temor, por tener que hacer un discurso como este donde se esconden peligros de variada índole derivados de cómo son las cosas puesto que en ellas siempre hay a lo menos dos caras, razones o apreciaciones. Así, entre otras,

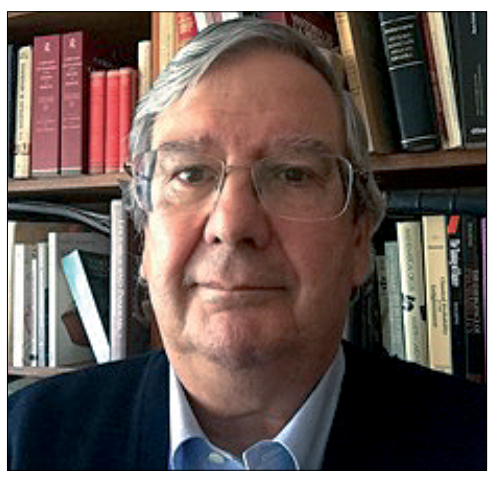

como consideraciones y restricciones preliminares para conseguir el propósito de salir honrosamente de este paso: que no sea muy largo pues todos están ya pensando en el cóctel, pero tampoco tan corto que sea opaco o limitado a lugares comunes, predecibles e insulsos; que no sea muy personal para que pueda ser percibido como pavoneo, pero tampoco tan impersonal que parezca una clase o un comercial; que mencione a todos a quienes es necesario agradecer pero que no vaya a olvidar a alguien que lo merezca; y, en fin, un discurso que quizás haga sonreir sin que le reste solemnidad a la ocasión, que ojalá mueva alguna reflexión y también, idealmente, evoque alguna emoción. Dicho esto, quisiera compartir con ustedes una leyenda, algunas reflexiones sobre la anestesiología y la historia de la medicina, para terminar con lo que quiero, anhelo, y debo reconocer públicamente.

La leyenda es la de Mitrídates VI Eupator llamado el Grande, rey del Ponto en las costas del Mar Negro en el último siglo $\mathrm{aC}$, formidable enemigo de Roma y quien resistió con éxito diversos intentos de conquista. Se cuenta que el rey sentía gran temor de ser envenenado, cosa nada extraña en aquellos tiempos y porque el mismo se habría despejado el camino al trono por ese medio. Así, experimentaba con diversas substancias, en esclavos, prisioneros y en el mismo, con el objeto de desarrollar inmunidad. Hecha la investigación 
y las conclusiones, diariamente ingería pequeñas cantidades de todos los venenos conocidos formulados en una pócima secreta; supongo podemos considerarlo el primer homeópata. Cuando finalmente los romanos lo vencieron, le dió veneno a sus hijas antes de tomar el mismo una gran cantidad para evitar que fuesen capturados con vida. En ellas, el efecto fue rápido y fatal pero el rey debió pedir a uno de sus guardias que usara la espada para conseguir su propósito. La pócima pasó a la historia como el mitridatium y luego, en tiempos de Galeno y con algunos ingredientes más, como la triaca que se usó hasta el siglo XIX; modernamente contiene ácido hialurónico y se vende contra la celulitis y las arrugas. Plinio el Viejo, en su Historia Naturalis, unos cien años después, describe que cuando Pompeyo entró en la recámara del rey encontró la receta de su antídoto citando, entre otros ingredientes, nueces, higos y veinte hojas de ruda macerados y con una pizca de sal... cum grano salis. No queda claro si la receta incluía la sal para ser efectiva, como las hojas de coca necesitan ceniza para liberar su alcaloide o, como se ha interpretado desde entonces, que es necesario tomar la receta y la historia con algún grado de escepticismo. Este relato introductorio, que por cierto como buena leyenda tiene diversos niveles de lectura, sirve como metáfora para introducir esas reflexiones sobre la anestesiología; la primera, sobre los posibles resultados de ser nombrado maestro, las otras sobre diversos tóxicos y venenos que afectan a la especialidad o a quienes la ejercen y comentar sobre algunos antídotos para contrarrestarlos. Les ruego sean benevolentes con algunas citas que he incluido por ser atingentes, por dar crédito a quien corresponde, y porque están escritas de manera inmejorable.

En el Diccionario de la Real Academia Española de la Lengua del 2001, la última que tengo en papel, se describen 23 acepciones para la palabra maestro o, para respetar aquello de la igualdad de géneros, maestra. La primera hace referencia a una persona o a una obra de mérito relevante entre los de su clase; mientras verificaba esta definición, se me vinieron a la mente dos metáforas al respecto que explican aquello del pudor y cómo funciona y debe funcionar ese cum grano salis. Una, atribuída a Newton, aunque tiene una estirpe más larga y complicada, quien comentando sus no menores contribucio- nes dijo en la Royal Society: "He logrado ver más lejos que los demás pues estoy parado sobre los hombros de gigantes". Humberto Ecco, en el prólogo de un extraordinario libro de Robert Merton, unos de los padres de la sociología y gran historiador de la ciencia, titulado precisamente "Sobre los hombros de gigantes", que no puedo dejar de recomendar encarecidamente al igual que sus historias y aventuras de la serendipidad, hace el comentario que la frase puede sugerir humildad pero que también puede surgir desde la vanidad al afirmar que ha logrado ver más allá que los demás y eso que eran gigantes; algunos datos biográficos de Newton y sus disputas con sus contemporáneos hacen dudar que se trate simplemente de un reconocimiento a los aportes de los antecesores. Ortega y Gasset, en la segunda metáfora atingente y complementaria, al hablar de las sucesivas generaciones, decía que los hombres formamos una pirámide donde quienes están en la cima gozan de ello pero que harían bien en reconocer que son prisioneros de los demás; podríamos agregar que, inevitablemente, y más temprano que tarde, se pasa a ser de las filas que aquellos que, tembleques, soportan a otros sobre los hombros. Afortunadamente, la segunda acepción de maestro permite perfeccionar esta disyuntiva pues presta un perfecto balance a la primera citada cuando afirma de maestro, "dícese del irracional adiestrado", halcón maestro, perro maestro. Ante el intríngulis, es sano tomar todo honor o toda diatriba cum grano salis para intentar alcanzar o conservar esa aequanimitas que recomendaba Osler como rasgo deseable en cualquier ser humano pero indispensable en un médico. En cualquier caso, sólo por curiosidad, me encantaría saber cual de estas acepciones, o las dos, tomó en cuenta el directorio para su decisión.

La tercera acepción me complace plenamente cuando anota "dícese sobre la persona que enseña una ciencia, arte u oficio". Siento que esa es mi contribución principal a la anestesiología que tiene algo de las tres, parafraseando a Pellegrino, profesor emérito de Medicina y Ética Médica en Georgetown, quien dice con belleza inigualable: "la medicina es la más humana de las artes, la más científica de las humanidades y la más artística de las ciencias". Me gusta creer que he logrado integrar así lo que he sido y hecho en lo profesional y lo académico, y creer que esto ha sido 
un antídoto eficaz ante las tentaciones, límites y riesgos de ejercerla en una sola de estas disciplinas. Otra dimensión que me gustaría compartir pues a todo lo anterior agrega un sentido, aparece en una de las citas más manidas sobre el rol de un maestro como alguien que enseña. Es de Henry Adams, escritor e historiador bostoniano quien en su libro inconcluso La educación de Henry Adams escribe "un maestro afecta a la eternidad pues nunca se sabe hasta donde puede llegar su influencia". Si bien lo dijo en un tono negativo reflexionando sobre cómo su educación del siglo XIX no lo había preparado para los desafíos del siglo XX con la irrupción de la ciencia y la tecnología, ha sido tomada más bien en un sentido positivo, de como quien enseña puede llegar a modificar esa eternidad a través de sus discípulos y por ello ha inspirado a generaciones de maestros. Me place pensar que esto pudiese ser cierto en mi caso, aunque sea en una mínima parte y sin una pizca de vanidad, pues es la imagen más potente a la que puedo asirme para justificar mi carrera académica y mi contribución a la misión de la universidad. Todo lo que pueda haber contribuido ojalá haya redundado en mejores anestesiólogos, en el sentido más amplio de la palabra, pues ellos cuidarán mejor a los pacientes que les toque atender y, a su vez, formarán a otros en ese mismo devenir.

Para cerrar lo de venenos y antídotos, quisiera hablar algo sobre la importancia de la historia de la medicina en la formación y en la práctica de todo médico. Durante buena parte de mi ejercicio académico y profesional pensaba que la historia de la medicina era mas bien fome, poco más que una sucesión de nombres y fechas que aparecían en las primeras páginas de los libros o en las diapositivas introductorias de una charla, meros datos doctos que, si bien podían tener algún interés pasajero, tenían poca o ninguna relevancia con el ejercicio de la medicina. Diversas circunstancias me llevaron a investigar sobre la historia de la anestesia local, actividad que dio origen a varias charlas y artículos. Cuando concluí, me di cuenta cuán equivocado había estado al juzgar algo o a alguien, una vez más, superficialmente y con ignorancia, sin duda alguna una forma de arrogancia. Muchos piensan que dedicar tiempo a la historia de la disciplina es sólo un hobby como podría ser el golf, el pilates o qué se yo, la lucha libre como lo hacía John
Bonica, un mero placer personal, un pasatiempo que se practica fuera de las horas de trabajo. Otros consideran que, si bien algo más que un hobby, sigue siendo una actividad optativa como pueden ser las matemáticas o la astronomía, y desde luego otras humanidades, todas con indudables dividendos, en lo personal y también en lo profesional, pues a través de ellas, se arguye, se fomenta aquello que en los últimos años se ha dado en llamar profesionalismo, un antídoto ante la creciente despersonalización de la medicina, causa de insatisfacción de los pacientes y de aburrimiento, mercantilización, falta de interés por mantenerse al día y, finalmente, burnout en los médicos. Pienso que los anestesiólogos, como cualquier especialista que actúa solo y que necesita y usa la tecnología intensivamente en su práctica diaria, estamos particularmente expuestos y nos cuesta detectar como estos tóxicos van adormeciendo la empatía y la reflexión sobre lo que se hace y cómo se hace. Así, cada vez es más fácil perder de vista el ser humano escondido detrás de su $\mathrm{CO}_{2}$, su ECG, su temperatura o su EVA, o bien, detrás de una yugular, una arteria o una espalda que pinchar. Ante esta realidad, muchos han sugerido como antídoto el cultivo de las humanidades y en esto, el estudio y la reflexión sobre la historia tiene efectos que van más allá de los acontecimientos del pasado y la transforman en una dedicación no sólo deseable sino que, me gusta pensar, imprescindible. Henry Sigerist, ese gran historiador de la medicina de la primera mitad del siglo XX, escribió la siguiente frase, irredargüible; dice: "Quien penetra en la historia de la Medicina se ve enfrentado a una diversidad de facetas del mundo del hombre: idiomas, geografía, religión, filosofía, política, ciencia, artes, y la influencia mutua entre ellos y de su relación con la Medicina...". Es evidente que la historia engloba entonces a todas las humanidades y que comprender y reflexionar sobre estas dimensiones del mundo del hombre es por fuerza relevante e indispensable para un profesional de la salud, más, o a lo menos igualmente importante, que la semiología, la biología molecular o la fisiopatología. Para mi, esto ha sido como encontrar un tesoro incalculable y tan feliz de encontrarlo que lo único que quiero es compartir su riqueza con quien quiera escucharme.

Quisiera terminar con los reconocimientos a quienes me han ayudado a desarrollarme como 
persona y como profesional hasta alcanzar este sitial de irracional adiestrado. En primer lugar, agradecer a esas mil circunstancias que modelan lo que llegamos a ser, las más de las veces sin que nos lo hayamos propuesto; para muchos es la suerte, el azar o el destino; para mi, la Divina Providencia que me ha dado una familia, una profesión y una misión. Gracias también a mi institución, la PUC, que me ha brindado las mejores condiciones posibles para recorrer el camino como anestesiólogo y también para perderme en esos otros derroteros paralelos como ha sido la filología, la bioestadística, la educación médica y la historia de la medicina donde he tratado de caminar lo más lejos posible y cavar lo más profundo que mis limitadas capacidades han permitido.

A quienes fueron motivo principal de mis preocupaciones $\mathrm{y}$, a la vez, aliciente permanente para seguir aprendiendo. A todos esos pacientes que sufrieron mis atenciones de quienes aprendí mil lecciones; a quienes de una o de otra manera me enseñaron y a todos quienes aprendieron algo de mí, algunos de cuyos rostros reconozco desde aquí, con toda, mi gratitud: si quieres aprender, enseña...decía Cicerón y con cuanta razón. A mis amigos, parafraseando a Unamuno en su Secreto de la vida, pues no lo puedo expresar mejor "cada nuevo amigo nos perfecciona y enriquece, mas aun que por lo que de el mismo nos da, por lo que de nosotros mismos nos descubre. Hay en cada uno de nosotros cabos sueltos espirituales, rincones del alma, escondrijos y recovecos de la consciencia que yacen inactivos e inertes...si no llega el que nos los despierte...". Dentro de tantos, que influyeron en la formación del departamento de anestesiología y también en mi desarrollo personal, por magnitud y duración de los afectos, quisiera recordar, reconocer y agradecer con gran afecto a José De la Fuente y a Samuel Torregrosa pues con ellos compartí desvelos, preocupaciones y, especialmente, tantas risas sobre todo de nosotros mismos... práctica y recuerdo cuotidiano de ese cum grano salis. Por ultimo pero ni con mucho por menor importancia, pues son los únicos para quienes soy único, gracias a mi familia, a mis padres que seguramente están orgullosos, a mis hijos y nietos, que alumbran aún en las horas oscuras, y a mi esposa por su amor y apoyo a lo largo de todo este ya largo y apasionante camino. 